\section{Hippocampal Ischemic Transient Global Amnesia after Gastrointestinal Endoscopy without Prior Medication}

\section{Abstract}

Background: Transient global amnesia (TGA) is a clinically amnestic syndrome characterized by normal neurological function aside from sudden-onset, reversible anterograde amnesia during the episode. TGA is typically related to strenuous physical activity, severe emotional stress and some medical procedures, such as angiography, while reports of TGA related to gastrointestinal (GI) endoscopy are extremely rare.

Method: I analyzed the clinical features and the neuro-radiological findings of three cases of TGA after GI endoscopy without prior medication.

Results: I described three cases of clinically confirmed TGA after upper GI endoscopy or colonoscopy, and all three patients presented with tiny ischemic unilateral or bilateral lesions in their hippocampus on DWI of the brain.

Conclusion: TGA must be considered in amnestic patients after $\mathrm{Gl}$ endoscopy, and prompt DWI of the brain may be helpful for diagnosing TGA.

Keywords: Transient Global Amnesia (TGA); Gastrointestinal (GI) endoscopy; Colonoscopy; Tiny ischemic lesion; Hippocampus

\author{
Won Tae Yoon* \\ Department of Neurology, Kangbuk \\ Samsung Hospital, Sungkyunkwan University \\ School of Medicine, Seoul, Republic of Korea
}

*Corresponding author: Won Tae Yoon

wtyoon@gmail.com

Department of Neurology, Kangbuk Samsung Hospital Sungkyunkwan University School of Medicine, \#29 Saemunan-ro, Jongno-gu, Seoul 03181, Republic of Korea.

Tel: $+82-2-2001-1938$

Fax: $+82-2-2001-2988$

Citation: Yoon WT (2017) Hippocampal Ischemic Transient Global Amnesia after Gastrointestinal Endoscopy without Prior Medication. J Neurol Neurosci. Vol. 8 No. $5: 222$

Received: September 28, 2017; Accepted: October 09, 2017; Published: October 13, 2017

\section{Introduction}

Transient global amnesia (TGA) is a clinically amnestic syndrome characterized by sudden-onset, reversible anterograde amnesia during the episode without alterations in level of consciousness and focal neurologic deficits [1]. The diagnosis of TGA is established based on its clinical features, and typically, a discrete episode of anterograde amnesia is accompanied by repetitive questioning and resolution of the symptoms within 24 hours [1,2].

The etiology of TGA is still not clear. Some pathophysiological mechanisms have been proposed, including brain focal ischemia, migraine, venous flow abnormalities, epileptic phenomena and psychological disturbances [2-4]. Recent high-resolution neuroimaging data have suggested that memory circuits in the mesial temporal region are involved because hyperintense MRI lesions have been detected in the hippocampal formations of TGA patients [5-7].

TGA is usually related to strenuous physical activity and severe emotional stress. Some cases reports have stated that amnestic symptoms are often precipitated by not only "Valsalva-like" physical activity, such as heavy lifting, sexual intercourse, coughing or swimming, but also psychological trauma or emotional stress [8-12]. Moreover, relatively rare conditions associated with TGA have been reported, including prolonged and abnormal head posture, sudden immersion in cold or hot water, severe pain and some medical procedures, such as angiography and gastrointestinal (GI) endoscopy [12-18]. However, in these case reports, most patients had normal brain imaging results, and medical procedures alone could not be considered the main cause of TGA due to the use of prior medications or previous medical conditions.

In this report, I describe two cases of TGA after GI endoscopy without prior medication except for oral lidocaine spray and one case of TGA after colonoscopy without prior medication. All three previously healthy patients were confirmed to have tiny ischemic unilateral or bilateral lesions in their hippocampus on diffusionweighted imaging (DWI) of the brain. 


\section{Methods and Case Series}

I analyzed the clinical features and the neuro-radiological findings of three cases of TGA after GI endoscopy without prior medication.

\section{Case 1}

A previously healthy 66-year-old woman visited our hospital for a general medical examination and underwent an upper GI endoscopy without prior medication that demonstrated she had antral mucosal hyperemia. After the endoscopy, she experienced retrograde amnesia as well as anterograde amnesia, and the symptoms were observed by her relatives and the medical staff in internal medicine. She repetitively inquired, "Where is here?" or "Who would take me home?" She had no difficulty recognizing her relatives. Five hours later, her memory slowly returned to normal, except for her memory of the first 2 hours of the episode (from the beginning of endoscopy to arriving home).

The next day, she was referred to our department and examined via brain imaging. The neurological examination and routine blood laboratory findings were normal, and her Mini-Mental Status Examination (MMSE) score was 29. DWI of the brain revealed a tiny lesion with high signal intensity in the left medial hippocampus (Figure 1A). Thus, she was clinically diagnosed with TGA. She was placed on a medication of aspirin for preventive purpose and remained asymptomatic at 12 months follow-up.

\section{Case 2}

A previously healthy 47-year-old man visited the emergency department of our hospital due to acute onset amnesia. He underwent an upper Gl endoscopy without prior medication during a general medical examination at a local primary hospital. After the endoscopy in the morning, he returned to his office for his daily work schedule. However, while he was working in his office, he presented signs of retrograde amnesia as well as anterograde amnesia, and the symptoms were first observed by his colleagues. He repetitively inquired, "Where is here?", "What time is it?", or "How did I get here?" He had no difficulty recognizing his colleagues and family. Approximately 7 hours later, his memory slowly returned to normal, except for his memory of the first 4 hours of the episode (from the beginning of endoscopy to arriving at the emergency room of the hospital).

On that day, he was referred to our department and examined, and he underwent brain imaging two days later. His neurological examination and routine blood laboratory findings were normal, and his MMSE score was 30. DWI of his brain showed tiny bilateral lesions with high signal intensity in the medial hippocampus (Figure 1B). Thus, he was clinically diagnosed with TGA. He was placed on a medication of aspirin for preventive purpose and remained asymptomatic at 12 months follow-up.

\section{Case 3}

A previously healthy 63-year-old man visited our hospital for a general medical examination and underwent a colonoscopy without prior medication for a preventive evaluation of his colon and rectum. After the colonoscopy, he experienced faintness and amnesia. Within a few minutes, his consciousness improved to normal, but several retrograde and anterograde amnesia symptoms were observed by clinicians in internal medicine.

At that time, he was referred to our department and underwent brain imaging. His neurological examination results and routine blood laboratory findings were normal, and his MMSE score was 30. Within one hour of the onset of amnesia, his memory recovered to normal. DWI of the brain showed a tiny lesion with high signal intensity in his left medial hippocampus (Figure 1C). Thus, he was clinically diagnosed with TGA. He was placed on a medication of aspirin for preventive purpose and remained asymptomatic at 12 months follow-up.

\section{Results}

I described three cases of clinically confirmed TGA after upper GI endoscopy or colonoscopy, and all three patients presented with tiny ischemic unilateral or bilateral lesions in their hippocampus on DWI of the brain. I analyzed their clinical profiles and neuroradiological findings, which were compared to four cases of TGA after gastroscopy or upper GI endoscopy from two previous reports (Table 1).
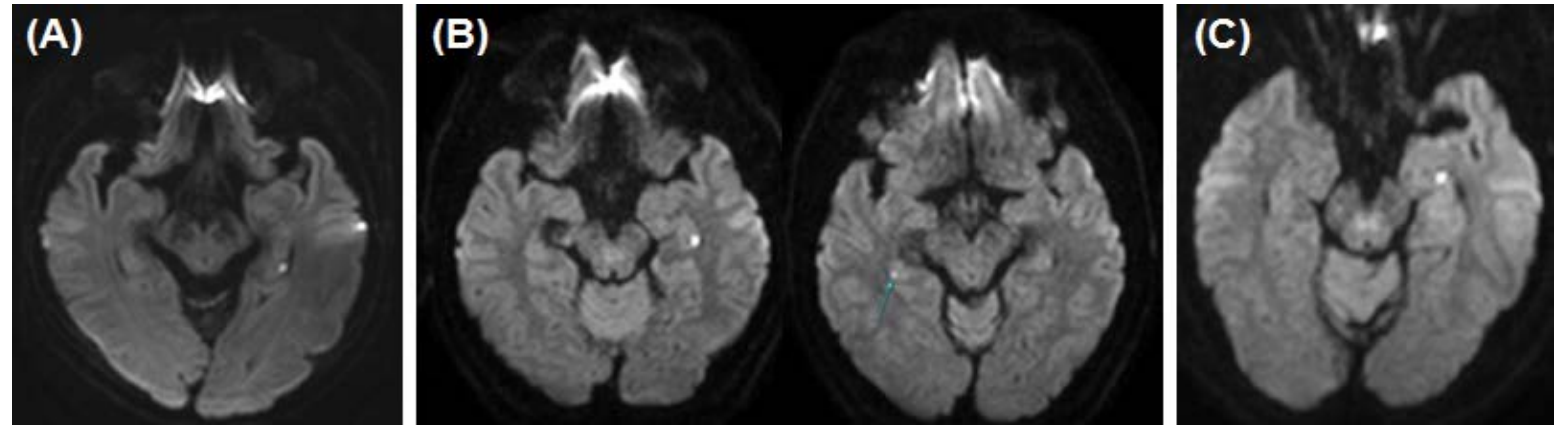

Figure 1 Axial diffusion-weighted MRI showing hippocampal ischemic lesions in all three patients. (A) Patient 1 had a left hippocampus lesion 38 hours after symptom onset, (B) Patient 2 had bilateral hippocampus lesions 53 hours after symptom onset and (C) Patient 3 had a left hippocampus lesion 2 hours after symptom onset. 
Table 1 Summary of the clinical features and MRI findings for TGA after GI endoscopy.

\begin{tabular}{|c|c|c|c|c|c|c|c|}
\hline Patients Characteristics & 1 & 2 & 3 & 4 & 5 & 6 & 7 \\
\hline Sex & Female & Male & Male & Female & Female & Female & Female \\
\hline Age (years) & 66 & 47 & 63 & 58 & 59 & 65 & 76 \\
\hline Type of endoscopy & $\begin{array}{l}\text { Upper GI } \\
\text { Endoscopy }\end{array}$ & $\begin{array}{l}\text { Upper GI } \\
\text { Endoscopy }\end{array}$ & Colonoscopy & Gastroscopy & Gastroscopy & Gastroscopy & $\begin{array}{l}\text { Upper GI } \\
\text { Endoscopy }\end{array}$ \\
\hline Vascular risk & None & None & None & $\mathrm{HTN}^{\mathrm{a}}$ & None & $\mathrm{HLD}^{\mathrm{b}}$ & $\mathrm{ASC}^{\mathrm{c}} / \mathrm{TR}^{\mathrm{d}}$ \\
\hline Episode duration (hours) & 5 & 7 & 1 & 7.5 & 15 & 8 & 12 \\
\hline Prior medication & None & None & None & None & $\mathrm{SB}^{\mathrm{e}}$ & $\mathrm{SB}^{\mathrm{e}}$ & None \\
\hline Pharyngeal lidocaine spray & Yes & Yes & Yes & Yes & Yes & Yes & Yes \\
\hline Initial MMSE ${ }^{f}$ & 29 & 30 & 30 & & & & \\
\hline $\begin{array}{l}\text { Hippocampal ischemic } \\
\text { lesion (on diffusion MRI) }\end{array}$ & Yes & Yes & Yes & Normal & Normal & Normal & Not checked \\
\hline $\begin{array}{l}\text { Location of hippocampal } \\
\text { ischemic lesion }\end{array}$ & Left & Bilateral & Left & -- & -- & -- & -- \\
\hline $\begin{array}{l}\text { Time of MRI from } \\
\text { onset of TGA (hours) }\end{array}$ & 38 & 53 & 2 & Unknown & 120 & 288 & -- \\
\hline Reference & Our study & Our study & Our study & [17] & [17] & [17] & [18] \\
\hline
\end{tabular}

\section{Discussion}

To date, only a few TGA cases associated with gastroscopy or GI endoscopy have been reported. However, most patients in these previously reported cases had vascular risk factors or prior medications before their endoscopy. Additionally, all patients had normal brain imaging without high signal lesions of the hippocampus, which may support neuro-radiological findings of TGA $[17,18]$. In contrast, all three of our patients presented hippocampal ischemic lesions on DWI of the brain. Additionally, to the best of my knowledge, the third patient in this report was the first case of TGA after colonoscopy without prior medication to be described in the English literature.

TGA was defined over 50 years ago [19], but the etiology and pathophysiology of this disorder are not completely understood [20]. Nevertheless, most precipitating events in the majority of TGA patients have been described as physical or emotional episodes, which have variable causes, including severe emotional stress, strenuous physical effort, acute pain, sharp temperature changes and sexual intercourse, among other activities.

Secondary TGA cases associated with some medical procedures or invasive treatments have been reported, including cerebral angiography [14-16], coronary angiography or angioplasty [21,22], transesophageal echocardiograms [23], saline- or druginduced transthoracic echocardiography [24,25], vertebral angioplasty/stenting [26], ablation therapy [27,28], and upper GI endoscopy $[17,18]$. Additionally, some case reports have described that certain anesthetic or erectile dysfunction drugs can cause secondary TGA [29-31]. However, most of the previously reported secondary TGA cases have normal brain imaging results, unlike our three cases with hippocampal ischemic lesions. We could presume the reason that MRI was delayed or performed inappropriately was that the previously recommended time window was 24-72 hours after the onset of TGA symptoms [2]. Other reports have described small punctate DWI lesions in the lateral aspects of the hippocampal formation that can also be detected before 48 hours after onset, as in our cases [3,32].

Generally, GI endoscopy procedures without prior medication can affect "Valsalva-like" activity and lead to a disturbance in venous blood flow due to intolerable nausea in the bent knee position produced by increased abdominal pressure. Published reports and hypotheses indicate that TGA could be caused by venous congestion accompanied by "Valsalva-like" activity $[9,33,34]$. Additionally, autonomic nervous system changes due to anxiety or rapid gastric dilation during the GI endoscopy procedure have been reported [35]. Based on these reasons and the clinical findings of our cases, a Gl endoscopy without prior medication may lead to TGA, even though the pathophysiological mechanism of TGA is still not clear.

On the other hand, if amnestic patients have vascular risk factors including abnormal vascular systems, coronary heart disease, coagulopathy or other direct aggravating vascular factors, further evaluations for vascular systems and hidden risk factors of thromboembolism should be considered for differential diagnosis of various neurological disorders. Recently some studies described importance of differential diagnosis between ischemic amnesia and TGA [36], and new concepts of pathogenesis of impaired posterior circulation and development of the brainstem ischemia in traumatic cervical spinal cord injury [37,38].

Regardless of the causes and etiologies, occurrences of different forms of transient amnesia, including TGA, are not rare $[39,40]$. However, if the amnestic symptoms quickly improve without other neurological symptoms, accurate diagnoses are difficult to achieve because mild amnestic patients may not visit a hospital or a neurology practice, and patients may not undergo further evaluation for a differential diagnosis of amnesia after the symptoms improve. All three of our patients had relatively mild amnestic symptoms with a shorter duration than other previously reported cases, but due to the occurrence of amnesia, prompt clinical diagnosis and rapid DWI of the brain could confirm the clinical diagnosis of TGA after GI endoscopy. 


\section{Conclusion}

Therefore, even without prior medication, GI endoscopy may precipitate TGA, as shown in these cases. Furthermore, if patients exhibit amnesia after a GI endoscopy, TGA must be considered in the initial differential diagnosis. In addition to neurologists, GI healthcare providers should also consider promptly performing

\section{References}

1 Hodges JR, Warlow CP (1990) The etiology of transient global amnesia. A case-control study of 114 cases with prospective followup. Brain 113: 639-657.

2 Bartsch T, Deuschl G (2010) Transient global amnesia: Functional anatomy and clinical implications. Lancet Neurol 9: 205-214.

3 Sander K, Sander D (2005) New insights into transient global amnesia: Recent imaging and clinical findings. Lancet Neurol 4: 437-444.

4 Pantoni L, Lamassa M, Inzitari D (2000) Transient global amnesia: A review emphasizing pathogenic aspects. Acta Neurol Scand 102 : 275-283.

5 Bartsch T, Alfke K, Deuschl G, Jansen O (2007) Evolution of hippocampal CA-1 diffusion lesions in transient global amnesia. Ann Neurol 62: 475-480.

6 Lee HY, Kim JH, Weon YC, Lee JS, Kim SY, et al. (2007) Diffusionweighted imaging in transient global amnesia exposes the CA1 region of the hippocampus. Neuroradiology 49: 481-487.

7 Yang Y, Kim S, Kim JH (2008) Ischemic evidence of transient global amnesia: Location of the lesion in the hippocampus. J Clin Neurol 4: 59-66.

8 Inzitari D, Pantoni L, Lamassa M, Pallanti S, Pracucci G, et al. (1997) Emotional arousal and phobia in transient global amnesia. Arch Neurol 54: 866-873.

9 Lewis SL (1998) Etiology of transient global amnesia. Lancet 352 397-399.

10 Rosler A, Mras GJ, Frese A, Albert I, Schnorpfeil F (1999) Precipitating factors of transient global amnesia. J Neurol 246: 53-54.

11 Maloy K, Davis JE (2011) "Forgettable" sex: A case of transient global amnesia presenting to the emergency department. J Emerg Med 41: 257-260.

12 Dohring J, Schmuck A, Bartsch T (2014) Stress-related factors in the emergence of transient global amnesia with hippocampal lesions. Front Behav Neurosci 8: 287.

13 Borelli P, Vedovello M, Lorenzi A, Deluca C, Fenzi F, et al. (2011) Transient global amnesia after prolonged and abnormal head posture. Clin Neurol Neurosurg 113: 330-331.

14 Foss SJ, Snoer AH, Wagner A, Hauerberg J (2014) Transient global amnesia after cerebral angiography still occurs: Case report and literature review. Radiol Case Rep 9: 988.

15 Duan H, Li L, Zhang Y, Zhang J, Chen M, et al. (2016) Transient global amnesia following neural and cardiac angiography may be related to ischemia. Biomed Res Int 2016: 2821765.

16 Tiu C, Terecoasa EO, Grecu N, Dorobat B, Marinescu AN, et al. (2016) Transient global amnesia after cerebral angiography with iomeprol: A case report. Medicine (Baltimore) 95: e3590. an MRI including DWI for clinical confirmation of the diagnosis of TGA.

\section{Conflict of Interest}

The authors have no financial or personal relations that could pose a conflict of interest.

17 Hiraga A, Matsunaga T (2006) Transient global amnesia after gastroscopy. J Neurol Neurosurg Psychiatry 77: 995-996.

18 Sayilir A, Kurt M, Ibis M, Kekilli M, Onal IK, et al. (2009) Transient global amnesia following upper gastrointestinal endoscopy without premedication. Gastroenterol Nurs 32: 362.

19 Fisher CM, Adams RD (1964) Transient global amnesia. Acta Neurol Scand Suppl 40: 1-83.

20 Bartsch T, Alfke K, Stingele R, Rohr A, Freitag-Wolf S, et al. (2006) Selective affection of hippocampal CA-1 neurons in patients with transient global amnesia without long-term sequelae. Brain 129: 2874-2884.

21 Wong E, Patel A, Jayasinghe R (2005) Transient global amnesia following coronary angiography and angioplasty. Intern Med J 35 : 435-436.

22 Udyavar AR, D'Souza RC, Gadkar N, Rajani RM (2006) Transient global amnesia following coronary angiography. J Postgrad Med 52: 70-71.

23 Profice P, Rizzello V, Pennestri F, Pilato F, Della Marca G, et al. (2008) Transient global amnesia during transoesophageal echocardiogram. Neurol Sci 29: 477-479.

24 Venkatraman GK, Bauerschmidt A (2011) Two cases of delayedonset transient global amnesia after saline-contrast transthoracic echocardiography. Neurologist 17: 338-339.

25 Saura D, Penafiel P, Morales A, Albert L, Martinez F, et al. (2008) Transient global amnesia after dobutamine-atropine stress echocardiography. Eur J Echocardiogr 9: 567-568.

26 Kim HY, Kang HS, Roh HG, Oh J, Lee IK, et al. (2006) Transient global amnesia following vertebral artery angioplasty and stenting. Eur Neurol 56: 133-135.

27 Mokabberi R, Assal C, Afsaneh HM, Storm R, Dandamudi G (2010) Transient global amnesia after ablation of premature ventricular beats arising from the right coronary cusp. Indian Pacing Electrophysiol J 10: $372-375$

28 Chou CY, Chen CP, Huang CH (2012) Transient global amnesia after ablation of the left lateral accessory pathway. Indian Pacing Electrophysiol J 12: 69-72.

29 Ardila A, Moreno C (1991) Scopolamine intoxication as a model of transient global amnesia. Brain Cogn 15: 236-245.

30 Savitz SA, Caplan LR (2002) Transient global amnesia after sildenafil (Viagra) use. Neurology 59: 778.

31 Machado A, Rodrigues M, Ribeiro M, Cerqueira J, Soares-Fernandes J (2010) Tadalafil-induced transient global amnesia. J Neuropsychiatry Clin Neurosci 22: 328-352.

32 Sedlaczek O, Hirsch JG, Grips E, Peters CN, Gass A, et al. (2004) Detection of delayed focal MR changes in the lateral hippocampus in transient global amnesia. Neurology 62: 2165-2170.

33 Sander D, Winbeck K, Etgen T, Knapp R, Klingelhofer J, et al. (2000) 
Disturbance of venous flow patterns in patients with transient global amnesia. Lancet 356: 1982-1984.

34 Han K, Chao AC, Chang FC, Chung CP, Hsu HY, et al. (2015) Obstruction of venous drainage linked to transient global amnesia. PLoS One 10: e0132893.

35 Hayashi T, Nomura M, Honda H, Tezuka K, Torisu R, et al. (2000) Evaluation of autonomic nervous function during upper gastrointestinal endoscopy using heart rate variability. J Gastroenterol 35: 815-823.

36 Michel P, Beaud V, Eskandari A, Maeder P, Demonet JF, et al. (2017) Ischemic amnesia: Causes and outcome. Stroke 48: 2270-2273.

37 Salkov M, Tsymbaliuk V, Dzyak L, Rodinsky A, Cherednichenko Y, et al. (2016) New concept of pathogenesis of impaired circulation in traumatic cervical spinal cord injury and its impact on disease severity: case series of four patients. Eur Spine J 25: 11-18.

38 Salkov M, Zozylia N, Tsymbaliuk V, Dzyak L, Kozlov S, et al. (2015) New concept of the development of brainstem ischemia in the setting of occlusions of the vertebral arteries and radicular and medullary arteries in the presence of the cervical spinal injury. Brain Disord Ther 4: 193.

39 Quinette P, Guillery GB, Dayan J, De la Sayette V, Marquis S, et al. (2006) What does transient global amnesia really mean? Review of the literature and thorough study of 142 cases. Brain 129: 16401658.

40 Berli R, Hutter A, Waespe W, Bachli EB (2009) Transient global amnesia - Not so rare after all. Swiss Med Wkly 139: 288-292. 